ORIGINAL ARTICLE

\title{
Early pituitary-adrenal response and respiratory outcomes in preterm infants
}

\author{
P C Ng, C H Lee, C W K Lam, K C Ma, I H S Chan, E Wong, T F Fok
}

Arch Dis Child Fetal Neonatal Ed 2004;89:F127-F130. doi: 10.1136/adc.2002.021980

See end of article for authors' affiliations

Correspondence to:

Professor $\mathrm{Ng}$, Department of Paediatrics, Level 6, Clinical Sciences Building, Prince of Wales Hospital, Shatin, NT, Hong Kong; pakcheungng@ cuhk.edu.hk

Accepted 17 March 2003

\begin{abstract}
Objective: To assess the influence of circulating (basal) and stimulated plasma adrenocorticotrophin (ACTH) and serum cortisol on the duration of oxygen supplementation and development of chronic lung disease (CLD) in preterm, very low birthweight infants.

Methods: A total of 226 human corticotrophin releasing hormone stimulation tests were performed on 137 very low birthweight infants on days 7 and 14 in a tertiary neonatal centre.

Results: Multivariate regression analysis showed that the duration of oxygen supplementation was negatively associated with birth weight, but positively associated with alveolar-arterial oxygen gradient $\left(\mathrm{A}-\mathrm{aDO}_{2}\right)$ on the first day and with basal serum cortisol on day 14. In addition, the multivariate classification and regression trees model indicated that the two most useful indices for predicting CLD were clinical risk index for babies (CRIB) score (>9) and peak serum cortisol (>740 nmol/l) on day 14. The sensitivity, specificity, positive and negative predictive values of these factors for predicting CLD were 53\%, $80 \%, 81 \%$, and $70 \%$ respectively.

Conclusions: The findings suggest that birth weight, severity of initial respiratory failure as reflected by the $\mathrm{A}-\mathrm{aDO}_{2}$ gradient, and continuing "stress" with persistent increase in serum cortisol on day 14 are significant risk factors associated with the duration of oxygen supplementation, whereas early pituitaryadrenal response (basal and peak plasma ACTH and serum cortisol on day 7) is not an independent risk factor. Although CRIB score in combination with peak serum cortisol on day 14 are useful predictors of $C L D$, the need to use a stimulation test and the relatively late timing of the forecast render these indices unattractive for routine clinical use.
\end{abstract}

$\mathrm{N}$ ormal development of the hypothalamic-pituitaryadrenal (HPA) axis is essential for regulation of intrauterine homoeostasis, and timely differentiation and maturation of vital organ systems, including cardiovascular, pulmonary, and central nervous system, is necessary for extrauterine survival. ${ }^{1}$ A proportion of extremely preterm infants, however, may suffer from transient adrenocortical insufficiency of prematurity (TAP), ${ }^{2}$ with low circulating cortisol concentrations and raised cortisol precursors resulting from deficiency of intermediate enzymes of cortisol synthesis in the early postnatal period. ${ }^{3-6}$ Very low birthweight (VLBW) infants with TAP often have refractory systemic hypotension that is resistant to volume expansion and inotrope treatment, but respond promptly to corticosteroid replacement. ${ }^{78}$ Endogenous cortisol is an important anti-inflammatory hormone. The use of postnatal corticosteroids has been shown to suppress the production of cytokines and markers of lung inflammation in infants who develop chronic lung disease (CLD). ${ }^{910}$ Thus, an inability to secrete adequate amounts of glucocorticoid in early postnatal life may contribute to insufficient suppression of pulmonary inflammation secondary to volume or barotrauma and free radical oxidative damage, resulting in microvascular protein leakage, pulmonary fluid retention, and exaggerated lung injury with prolonged oxygen dependency. ${ }^{11}{ }^{12}$ This prospective study therefore aimed to evaluate the influence of circulating (basal) and stimulated HPA axis hormones, adrenocorticotrophin (ACTH) and cortisol, on (a) the duration of oxygen supplementation and $(b)$ the development of CLD in preterm, VLBW infants using the human corticotrophin releasing hormone (hCRH) test.

\section{PATIENTS AND METHODS}

\section{Study population}

A total of 137 VLBW infants were prospectively enrolled into the study. The patient recruitment process has been described in detail in the preceding paper. ${ }^{2}$ Table 1 presents the clinical characteristics of the infants studied.

\section{Methodology and data collection}

The hCRH test and hormone assays have been described in detail in previous studies. ${ }^{213}$ The following respiratory indices were documented during the study period: the highest oxygenation index and alveolar-arterial oxygen gradients $\left(\mathrm{A}-\mathrm{aDO}_{2}\right)$ within the first 12 hours of life; duration of mechanical ventilation and oxygen supplementation; maximum peak inspiratory pressure ( $\left.\mathrm{PIP}_{\max }\right)$, maximum mean airway pressure $\left(\mathrm{Paw}_{\max }\right)$, and maximum inspired oxygen concentration $\left(\mathrm{FIO}_{2} \mathrm{MAX}\right)$ within the first 14 days of life; use of postnatal systemic corticosteroids for facilitation of extubation; serious pulmonary complications such as pneumothorax, pulmonary interstitial emphysema, and pulmonary haemorrhage. CLD in this study is defined as oxygen dependency at 36 weeks postconceptional age. As CLD and death before 36 weeks postconceptional age are competitive outcomes, infants with either conditions were combined and analysed as a single group. Infants who

Abbreviations: $\mathrm{A}-\mathrm{aDO}_{2}$, alveolar-arterial oxygen gradient; $\mathrm{ACTH}$, adrenocorticotrophin; CART, classification and regression trees; CLD, chronic lung disease; $h C R H$, corticotrophin releasing hormone; HFOV, high frequency oscillatory ventilation; HPA, hypothalamic-pituitaryadrenal; IPPV, intermittent positive pressure ventilation; TAP, transient adrenocortical insufficiency of prematurity; VLBW, very low birthweight 
Table 1 Comparison of the clinical characteristics, respiratory indices, and outcomes of infants with chronic lung disease (CLD) or who had died (group 1) and those without CLD (group 2)

\begin{tabular}{|c|c|c|}
\hline & Group $1(n=45)$ & Group $2(n=92)$ \\
\hline Gestational age (weeks) & $26.4(24.9-28.3)$ & $29.1(27.8-30.6)^{* *}$ \\
\hline Birth weight $(g)$ & $860(706-1148)$ & $\begin{array}{l}1168(1034- \\
1329)^{\star *}\end{array}$ \\
\hline $\operatorname{Sex}(M / F)$ & $27(60 \%): 18(40 \%)$ & $45(49 \%): 47(51 \%)$ \\
\hline $\begin{array}{l}\text { Mode of delivery } \\
\text { (caesarean section: } \\
\text { instrumental:normal) }\end{array}$ & $\begin{array}{l}17(38 \%): 0(0 \%): 28 \\
(62 \%)\end{array}$ & $\begin{array}{l}61(66 \%): 1(1 \%): 30 \\
(33 \%)^{* *}\end{array}$ \\
\hline $\begin{array}{l}\text { Birth order } \\
\text { (singleton:twins:triplets) }\end{array}$ & $40(89 \%): 4(9 \%): 1$ (2\%) & $\begin{array}{l}70(76 \%): 20 \\
(22 \%): 2(2 \%)\end{array}$ \\
\hline Inborn:outborn & $44(98 \%): 1(2 \%)$ & $89(97 \%): 3(3 \%)$ \\
\hline $\begin{array}{l}\text { Prolonged rupture } \\
\text { membrane }>24 \text { hours }\end{array}$ & $10(22 \%)$ & $18(20 \%)$ \\
\hline Pre-eclampsia & $3(7 \%)$ & $15(16 \%)$ \\
\hline Antepartum haemorrhage & $7(16 \%)$ & $15(16 \%)$ \\
\hline \multicolumn{3}{|c|}{ Apgar scores } \\
\hline $1 \mathrm{~min}$ & $5(4-7)$ & $7(5-8)^{\star *}$ \\
\hline $5 \mathrm{~min}$ & $8(7-9)$ & $9(8-9)^{*}$ \\
\hline \multicolumn{3}{|c|}{ Antenatal dexamethasone } \\
\hline Cumulative doses (mg) & $20(0-40)$ & $20(20-38)$ \\
\hline $\begin{array}{l}\text { Time between last dose } \\
\text { and delivery (h) }\end{array}$ & $30(5-50)$ & $13(4-52)$ \\
\hline \multicolumn{3}{|l|}{$\begin{array}{l}\text { Respiratory indices and } \\
\text { outcomes }\end{array}$} \\
\hline CRIB score & $5(2-10)$ & $2(1-4)^{\star *}$ \\
\hline Ol (first 12 hours) & $7.7(4.1-12.3)$ & $4.7(2.0-10.0)^{*}$ \\
\hline $\begin{array}{l}\text { A-aDO} 2 \text { gradient (first } \\
12 \text { hours) }\end{array}$ & $250(125-373)$ & $123(47-261)^{\star *}$ \\
\hline $\begin{array}{l}\text { Mechanical ventilation } \\
\text { (day 7):no ventilation and } \\
\text { CPAP } \vee \text { IPPV and HFOV }\end{array}$ & $16(36 \%): 29(64 \%)$ & $\begin{array}{l}63(68 \%): 29 \\
(32 \%)^{* *}\end{array}$ \\
\hline $\begin{array}{l}\text { Duration of mechanical } \\
\text { ventilation (days) }\end{array}$ & $34(20-70)$ & $16(7-34)^{* *}$ \\
\hline $\begin{array}{l}\text { Duration of oxygen } \\
\text { supplementation (days) }\end{array}$ & $43(28-87)$ & $9(3-18)^{* *}$ \\
\hline PIP $_{\max }$ (first 14 days) & $23(20-25)$ & $20(18-24)^{\star \star}$ \\
\hline Paw max (first 14 days) & $12(10-15)$ & $10(8-13)^{\star *}$ \\
\hline $\mathrm{FlO}_{2} \operatorname{MAX}$ (first 14 days) & $0.90(0.79-1.00)$ & $0.50(0.36-0.64)^{* *}$ \\
\hline Postnatal corticosteroids & $31(69 \%)$ & $12(13 \%)^{* *}$ \\
\hline Pneumothorax & $7(16 \%)$ & $0(0 \%)^{* *}$ \\
\hline PIE & $12(27 \%)$ & $2(2 \%)^{* *}$ \\
\hline Pulmonary haemorrhage & $1(2 \%)$ & $2(2 \%)$ \\
\hline $\begin{array}{l}\text { Duration of hospital stay } \\
\text { (days) }\end{array}$ & $124(74-155)$ & $85(66-103)^{* *}$ \\
\hline Died & $18(40 \%)$ & $0(0 \%)^{* *}$ \\
\hline \multicolumn{3}{|c|}{$\begin{array}{l}\text { Results are median (interquartile range) or number (\%). } \\
* \mathrm{p}<0.01 \text { and }{ }^{*} \mathrm{p}<0.05 \text { compared with group } 1 . \\
\mathrm{CRIB} \text {, Clinical risk index for babies; OI, oxygenation index; } \mathrm{A}-\mathrm{aDO} \mathrm{O}_{2} \\
\text { alveolar-arterial oxygen gradient; } \mathrm{CPAP} \text {, continuous positive airway } \\
\text { pressure; } \mathrm{HFOV} \text {, high frequency oscillatory ventilation; IPPV, intermittent } \\
\text { positive pressure ventilation; } \mathrm{PIP}, \text { peak inspiratory pressure; Paw, airways } \\
\text { pressure; } \mathrm{FIO}_{2} \text {, fractional inspired oxygen; PIE, pulmonary interstitial } \\
\text { emphysema. }\end{array}$} \\
\hline
\end{tabular}

developed severe CLD and subsequently required postnatal systemic corticosteroid treatment were given a three week, dose tapering course of dexamethasone. ${ }^{14}$

\section{Ethical approval}

Ethical approval for the study was obtained from the clinical research ethics committee of the Chinese University of Hong Kong. Written informed parental consent was obtained for each case before the start of the test.

\section{Statistical analysis}

Spearman's correlation was used to assess the relation between duration of oxygen supplementation and $(a)$ circulating and stimulated hormone concentrations, $(b)$ pulmonary indices, and $(c)$ clinical characteristics of the studied infants. Univariate significant results $(p<0.05)$ were further subjected to multivariate regression analysis using a forward stepwise selection strategy. In addition, Mann-Whitney U test and $\chi^{2}$ tests were used to compare the clinical characteristics of the infants (table l) and hormone concentrations (table 2) of the infants with CLD or who had died (group 1) and infants without CLD (group 2). Significantly different results between the two groups (tables 1 and 2) were then subjected to the multivariate classification and regression trees (CART) model ${ }^{15}$ for assessing the usefulness of various factors in predicting CLD. CART is a non-parametric, binary recursive partitioning algorithm developed through a two stage process. A complex tree is initially constructed through a sequence of optimal binary splits of a set of covariates. These covariates are then partitioned recursively into two subgroups that are most different with respect to the outcome. The partitioning continues until the dependent variable is separated into homogeneous subgroups. The second stage prunes the resulting complex tree to an optimal subtree that minimises the overall classification error. This error rate is then estimated by a cross validation method and is implemented by a pruning algorithm. The statistical tests were performed by SPSS for Windows (Release 11.0; SPSS Inc, Chicago, Illinois, USA) and S-Plus 2000 (Release 3; Math Soft Inc, Seattle, Washington, USA) softwares. The analysis was performed on raw and logarithmically ( $\mathrm{Ln}$ ) transformed data where appropriate to correct the skewness of the results.

\section{RESULTS}

A total of 226 hCRH tests were performed on 137 preterm, VLBW infants on days 7 and 14 of postnatal age. The preliminary ACTH and cortisol results of this cohort have been compiled to provide a reference range for the hCRH test in VLBW infants. ${ }^{16}$ The results on the relation between hormones of the HPA axis and duration of oxygen supplementation or CLD have not been reported previously.

\section{Overall analysis}

The results of the study population were pooled and analysed. Univariate analysis using Spearman's correlation showed significant associations between duration of oxygen supplementation and the following: gestational age $(r=-0.57, \mathrm{p}<0.0001)$ or birth weight $(r=-0.52$, $\mathrm{p}<0.0001) ;$ Apgar score at one minute $(r=-0.34$, $\mathrm{p}<0.0001)$ and five minutes $(r=-0.29, \mathrm{p}<0.001)$; CRIB score $(r=0.48, \mathrm{p}<0.0001)$; oxygenation index $(r=0.34, \mathrm{p}<0.0001) ; \mathrm{A}-\mathrm{aDo}_{2}(r=0.41, \mathrm{p}<0.0001)$; $\mathrm{PIP}_{\max }(r=0.40, \mathrm{p}<0.0001) ; \mathrm{Paw}_{\max }(r=0.38$, $\mathrm{p}<0.0001)$; total antenatal dexamethasone dose $(r=-0.18, \mathrm{p}=0.04)$; duration between the last dose of antenatal dexamethasone and delivery $(r=-0.20$, $\mathrm{p}=0.04)$; total cumulative dose of dopamine $(r=0.31$, $\mathrm{p}<0.0001)$; total volume of crystalloid $(r=0.44$, $\mathrm{p}<0.0001)$; duration of inotropic support $(r=0.36$, $\mathrm{p}<0.0001)$; peak serum cortisol on day $7(r=-0.21$, $\mathrm{p}=0.02)$; basal and peak serum cortisol on day $14(r=0.29$, $\mathrm{p}=0.005$ and $r=0.33, \mathrm{p}=0.001$ respectively). These significant univariate parameters were further subjected to the multivariate forward stepwise linear regression model using duration of oxygen supplementation as the dependent variable. The results suggested that duration of oxygen supplementation was negatively associated with birth weight, but correlated positively with $\mathrm{A}-\mathrm{aDO}_{2}$ on the first day and basal serum cortisol on day 14 (table 3). Exclusion of the deaths-that is, infants who died before 36 weeks postconceptional age $(\mathrm{n}=8)$-did not in any way alter the results of the multivariate analysis.

\section{Group 1 v group 2}

Tables 1 and 2 summarise the clinical characteristics and hormone concentrations of groups 1 and 2. As expected, 
Table 2 Comparison of the hormone concentrations in infants with chronic lung disease (CLD) or who had died (group 1) and those without CLD (group 2) at days 7 and 14

\begin{tabular}{|c|c|c|c|c|c|c|}
\hline & \multicolumn{3}{|l|}{ ACTH (pmol/l) } & \multicolumn{3}{|l|}{ Cortisol (nmol/l) } \\
\hline & Basal & Peak & $\triangle \mathrm{ACTH}_{0-15}$ & Basal & Peak & $\Delta$ Cort $_{0-30}$ \\
\hline \multicolumn{7}{|l|}{ Day 7} \\
\hline Group 1 ( $n=39$ ) & $5.3(3.4-6.7)$ & $9.3(7.4-15.5)$ & $4.0(1.9-9.1)$ & 208 (137-356) & $451(295-600)$ & $157(74-236)$ \\
\hline Group $2(\mathrm{n}=86)$ & $5.6(4.0-7.0)$ & $9.7(7.6-13.6)$ & $4.0(1.8-6.8)$ & 242 (163-422) & 489 (343-643) & 197 (116-277) \\
\hline \multicolumn{7}{|l|}{ Day 14} \\
\hline Group 1 ( $n=32$ ) & $7.1(4.7-10.9)$ & $12.2(9.1-16.4)$ & $3.3(1.7-7.1)$ & $315(238-507)$ & $579(387-790)$ & 189 (136-283) \\
\hline Group $2(\mathrm{n}=69)$ & $7.0(4.7-9.3)$ & $14.0(9.1-17.7)$ & $5.0(3.3-8.1)$ & $232(150-320)^{*}$ & $438(315-556)^{*}$ & $199(115-295)$ \\
\hline
\end{tabular}

group 1 infants were significantly more immature and sick than patients of group 2 (table 1). Although there were no significant differences in plasma ACTH between the groups, both basal and peak serum cortisol on day 14 were significantly raised in group 1 infants $(\mathrm{p}<0.01$; table 2$)$. The multivariate CART model suggested that the two most useful indices for predicting CLD were CRIB score $>9$ and peak serum cortisol $>740 \mathrm{nmol} / \mathrm{l}$ on day 14 . The sensitivity, specificity, positive and negative predictive values of using these indices for the prediction were 53\%, 80\%, $81 \%$, and $70 \%$ respectively.

\section{DISCUSSION}

Our previous report on the same cohort of VLBW infants indicated that plasma ACTH concentrations in the first week of life (day 7) were significantly higher in patients with severe respiratory distress syndrome (who required intermittent positive pressure ventilation (IPPV) or high frequency oscillatory ventilation (HFOV)) than in those who had milder pulmonary diseases and did not require mechanical ventilation or needed only continuous positive airway pressure support. ${ }^{16}$ In addition, infants who required IPPV/ HFOV had significantly lower serum cortisol on day 7, but this pattern of cortisol response was reversed by day $14 .^{16}$ Thus, the enhanced ACTH response on day 7, and the change in the pattern of cortisol response in sick ventilated infants during the first 14 days of life suggested that a proportion of VLBW infants may have transient inadequate adrenal response (TAP) to stress in the early postnatal period. Whether infants with prolonged oxygen requirement or CLD are more likely to have lower serum cortisol during the first week of life, compared with non-CLD infants, was being investigated in this study.

We found a significant negative association between duration of oxygen supplementation and peak serum cortisol on day 7 . This negative relation was reversed one week later, with both basal and peak serum cortisol on day 14 being positively related to oxygen supplementation. However, multivariate regression analysis showed that the duration of oxygen requirement by preterm infants was more significantly influenced by birth weight, severity of the initial

Table 3 Results of multivariate regression analysis

\begin{tabular}{lllll}
\hline & \multicolumn{3}{l}{ Ln (Duration of oxygen supplementation) } \\
\cline { 2 - 5 } & Coefficient & SE & P Value & $\boldsymbol{R}^{2}$ (\%) \\
\hline Birth weight & -0.0032 & 0.0004 & $<0.001$ & 50.1 \\
A-aDO $_{2}$ & 0.0026 & 0.0008 & 0.001 & - \\
Basal serum cortisol (day & 0.0011 & 0.0004 & $<0.001$ & - \\
$14)$ & & & & \\
\hline SE, standard error. & & & & \\
\hline
\end{tabular}

pulmonary condition as reflected by the $\mathrm{A}-\mathrm{aDO}_{2}$ gradient on the first day, and sustained stress as indicated by persistent increase in serum cortisol on day 14, rather than the concentrations of the hormones of the HPA axis on day 7 . Thus, the overall picture suggested that infants with low serum cortisol concentrations in the first week (TAP) tended to have severe respiratory distress syndrome and required IPPV/HFOV. ${ }^{16}$ However, low serum cortisol (day 7) per se did not necessarily translate into longer duration of oxygen requirement, as other aforementioned risk factors appeared to have a greater effect on the complex pulmonary inflammatory response and occurrence of CLD. These findings closely resemble the results of recent studies, which also showed that low gestational age or birth weight and adverse early respiratory mechanics, including low arterial/ alveolar oxygen ratio and high airway resistance before surfactant, were associated with an increased risk of CLD. ${ }^{17}$

In recent years, various investigators have attempted to assess the relation between basal or stimulated serum cortisol and the risk of development of CLD. Huysman et al showed a significantly lower mean cortisol concentration and higher cortisol precursor concentration in infants who subsequently developed CLD (defined as requirement of oxygen supplementation at 28 days). Similarly, Watterberg and Scott $^{11}$ reported that VLBW infants who developed chronic lung injury had significantly reduced cortisol responses to ACTH stimulation on day 5-7 compared with infants who did not. The same investigators in a second study further showed that the basal cortisol concentration measured during the latter half of the first week correlated inversely with $(a)$ the postconceptional age at which the infants stopped receiving supplemental oxygen and $(b)$ the concentrations of pulmonary inflammatory markers, including interleukins $1 \beta, 6$, and 8 , albumin, and total protein, obtained from tracheal lavage. ${ }^{12}$ Korte $e a^{18}$ studied infants of less than 32 weeks gestation and suggested that those infants with cortisol concentration $<414 \mathrm{nmol} / \mathrm{l}(<15 \mu \mathrm{g} / \mathrm{dl})$ were more likely to develop CLD at 36 weeks. However, they were unable to show a significant association between cortisol responsiveness to ACTH and CLD ${ }^{18}$ More recently, Banks et a $l^{19}$ using a subset of infants in the North American thyrotropin releasing hormone collaborative trial showed a borderline but non-significant negative association between unstimulated cortisol concentration measured on days 3-7 and CLD. Similarly, Romagnoli et $a l^{20}$ were unable to show a significant difference in plasma cortisol and ACTH on day 7 between infants who developed CLD and those who did not. There was also no significant correlation between hormones of the HPA axis and CLD, and these investigators discouraged the use of baseline or stimulated plasma cortisol for predicting the development of this condition. Our investigation is the first to use the hCRH test, a more sensitive HPA axis stimulation test, ${ }^{21}$ for evaluating both the pituitary and adrenal function in a 
relatively large cohort of VLBW infants. Although our univariate results showed a significant negative association between serum cortisol on day 7 and duration of oxygen supplementation, and to some extent supported the findings of Huysman et $a l^{5}$ and Watterberg et al, ${ }^{11}{ }^{12}$ the multivariate analysis showed that other risk factors, including birth weight (closely related to gestational age), severity of initial respiratory failure, and continuing stress at 2 weeks of age, were probably more important variables that correlated with the length of oxygen supplementation in preterm infants. Neither plasma ACTH nor serum cortisol on day 7, however, were independent risk factors. In addition, the lack of a significant difference in circulating and stimulated serum cortisol (day 7) between group 1 and group 2 infants (table 2) further suggested that the initial adrenal response was similar in infants who subsequently developed CLD and those who did not. We speculate that the discrepancies in results from various reports may be related to the different sample sizes and populations studied. However, the report of Banks et al ${ }^{19}$ and our study, which contained the two largest cohorts, did not show a significant association between ACTH or cortisol and duration of oxygen supplementation. Our subgroup analysis excluding infants over $1000 \mathrm{~g}$ also failed to show a significant relation (data not shown). In addition, the causes of CLD are complex with many interdependent risk factors and treatments. Factors such as lung immaturity, volume or barotrauma, oxygen toxicity, and use of natural surfactant and corticosteroids were all involved in modifying the pathogenic process and could influence the risk of developing CLD. Thus, endogenous cortisol is probably an insignificant or "weak" contributor, as suggested by Banks et $a l^{19}$ and the results of this study, and only one of many predisposing factors affecting the duration of oxygen supplementation and CLD.

In this study, we also assessed the use of ACTH or cortisol for prediction of CLD. CRIB score $>9$ in combination with peak serum cortisol $>740 \mathrm{nmol} / \mathrm{l}$ on day 14 were identified as the most useful indices. This combination has relatively good specificity $(80 \%)$, positive and negative predictive values ( $81 \%$ and $70 \%)$. Similarly, the CRIB score, which takes into account the gestational age and reflects the initial illness severity, together with continuing stress of high serum cortisol concentration at 2 weeks of age, were found to be specific predictors of CLD. However, the need to use an elaborated stimulation test and the relatively late timing of the forecast render these indices unappealing for routine clinical use.

In summary, this series of studies suggest that TAP, with low serum cortisol in the first week of life, is associated with severe respiratory distress syndrome and the need for IPPV/ HFOV. ${ }^{16}$ Despite this important relation, pituitary-adrenal response in the first week of life is not identified as an independent risk factor associated with the duration of oxygen supplementation. To shorten the duration of oxygen dependency in preterm infants, our results suggest targeting of management in three main areas: (a) prevention of premature delivery; $(b)$ optimising pulmonary condition at birth; (c) minimising the duration of stress, especially ventilatory stress, in VLBW infants. Although CRIB score and peak serum cortisol on day 14 are useful predictors of CLD, this combination is not attractive for routine clinical use.

\section{Authors' affiliations}

P C Ng, C H Lee, K C Ma, T F Fok, Department of Paediatrics, Prince of Wales Hospital, Chinese University of Hong Kong

C W K Lam, I H S Chan, Department of Chemical Pathology, Prince of Wales Hospital

E Wong, Centre for Clinical Trials and Epidemiological Research, Prince of Wales Hospital, Chinese University of Hong Kong

\section{REFERENCES}

$1 \mathrm{Ng}$ PC. The fetal and neonatal hypothalamic-pituitary-adrenal axis. Arch Dis Child Fetal Neonatal Ed 2000;82:F250-4.

$2 \mathrm{Ng}$ PC, Lee CH, Lam CWK, et al. Transient adrenocortical insufficiency of prematurity (TAP) and systemic hypotension in very low birth weight infants. Arch Dis Child Fetal Neonatal Ed 2003;89:000-000.

3 Hingre RV, Gross SJ, Hingre KS, et al. Adrenal steroidogenesis in very low birth weight preterm infants. J Clin Endocrinol Metab 1994;78:266-70.

4 Lee MM, Rajagopalan L, Berg GJ, et al. Serum adrenal steroid concentrations in premature infants. J Clin Endocrinol Metab 1989;69:1133-6.

5 Huysman MWA, Hokken-Koelega ACS, De Ridder MAJ, et al. Adrenal function in sick very preterm infants. Pediatr Res 2000;48:629-33.

6 Watterberg KL, Gerdes JS, Cook KL. Impaired glucocorticoid synthesis in premature infants developing chronic lung disease. Pediatr Res 2001;50:190-5.

7 Helbock HJ, Insoft RM, Conte FA. Glucocorticord responsive hypotension in extremely low birth weight newborns. Pediatrics 1993;92:715-17.

$8 \mathrm{Ng}$ PC, Lam CWK, Fok TF, et al. Refractory hypotension in preterm infants with adrenocortical insufficiency. Arch Dis Child Fetal Neonatal Ed 2001;84:F122-4.

9 Yoder MC, Chua R, Tepper R. Effect of dexamethasone on pulmonary inflammation and pulmonary function of ventilator-dependent infants with bronchopulmonary dysplasia. Am Rev Respir Dis 1991;143:1044-8.

10 Murch SH, MacDonald TT, Wood CB, et al. Tumour necrosis factor in the bronchoalveolar secretions of infants with the respiratory distress syndrome and the effect of dexamethasone treatment. Thorax 1992;47:44-7.

11 Watterberg KL, Scott SM. Evidence of early adrenal insufficiency in babies who develop bronchopulmonary dysplasia. Pediatrics 1995;95:120-5.

12 Watterberg KL, Scott SM, Backstrom C, et al. Links between early adrenal function and respiratory outcome in preterm infants: airway inflammation and patent ductus arteriosus. Pediatrics 2000; 105:320-4.

$13 \mathrm{Ng} \mathrm{PC}$, Wong GWK, Lam CWK, et al. The pituitary-adrenal responses to exogenous human corticotropin-releasing hormone in preterm, very low birth weight infants. J Clin Endocrinol Metab 1997;82:797-9.

14 Ng PC, Wong GWK, Lam CWK, et al. Pituitary-adrenal suppression and recovery in preterm very low birth weight infants after dexamethasone treatment for bronchopulmonary dysplasia. J Clin Endocrinol Metab 1997;82:2429-32.

15 Brieman I, Friedman JH, Olshen RA, et al. Classification and regression trees. New York: Chapman and Hall, 1993.

$16 \mathrm{Ng}$ PC, Lam CWK, Lee CH, et al. Reference ranges and factors affecting the hCRH test in preterm, very low birth weight infants. J Clin Endocrinol Metab 2002;87:4621-8.

17 Choukroun ML, Tayara N, Fayon M, et al. Early respiratory system mechanics and the prediction of chronic lung disease in ventilated preterm neonates requiring surfactant treatment. Biol Neonate 2003;83:30-5.

18 Korte C, Styne D, Merritt A, et al. Adrenocortical function in the very low birth weight infant improved testing sensitivity and association with neonatal outcome. J Pediatr 1996;128:257-63.

19 Banks BA, Stouffer N, Cnaan A, et al. Association of plasma cortisol and chronic lung disease in preterm infants. Pediatrics 2001;107:494-8.

20 Romagnoli C, Latella C, Zecca E, et al. Adrenocortical function and chronic lung disease of prematurity: an unsolved problem? J Endocrinol Invest 2002;25:759-64.

21 Karlsson R, Kallio J, Irjala K, et al. Adrenocorticotropin and corticotropinreleasing hormone tests in preterm infants. J Clin Endocrinol Metab 2000;85:4592-5. 